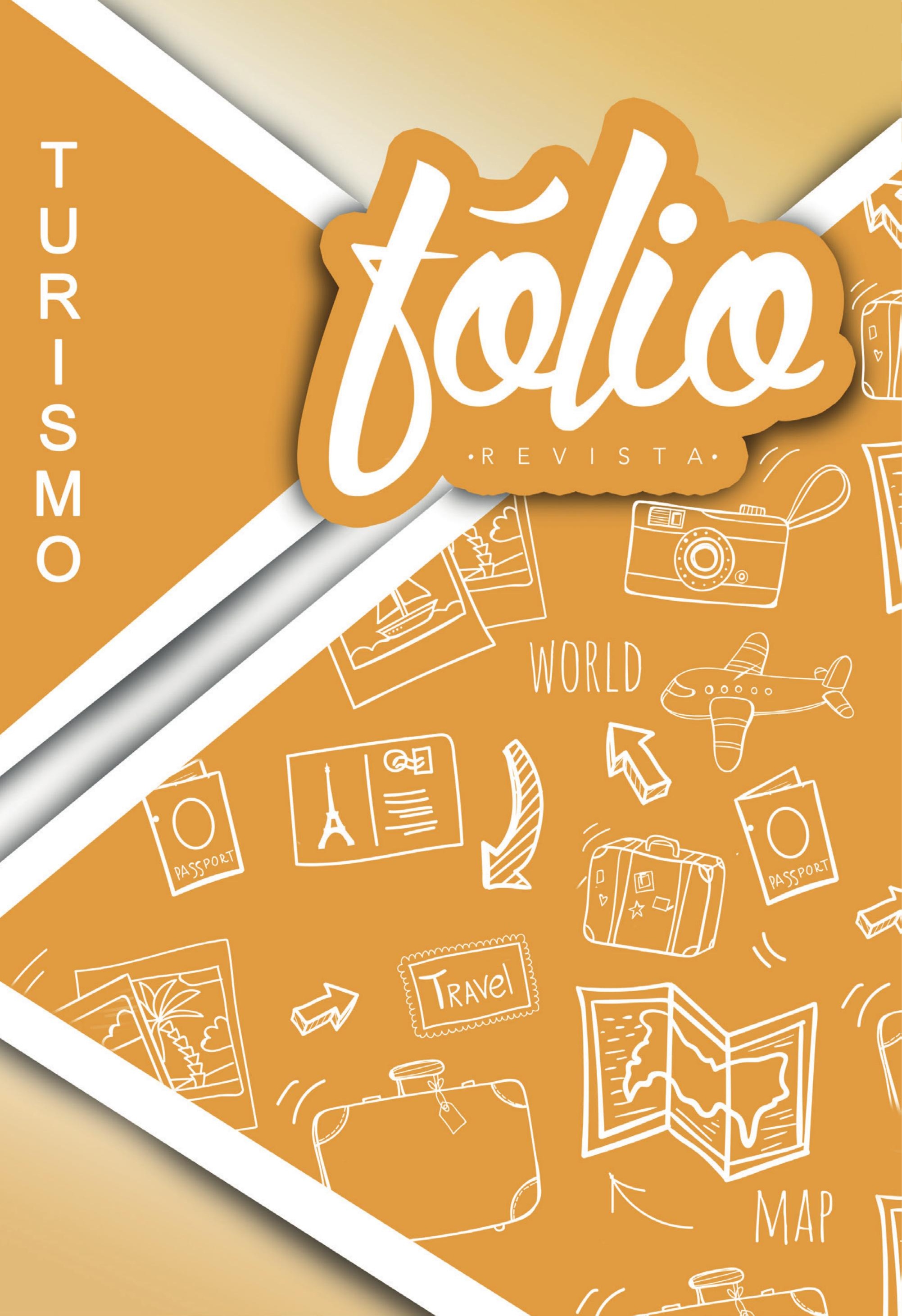




\title{
Divulgação e preservação do patrimônio geológico do geossítio Malacara Praia Grande (SC)
}

\section{Dissemination and preservation of the geological heritage of geoscite Malacara Praia Grande (SC)}

\author{
Marlon Nunes do Amaral ${ }^{1}$ \\ Leila Maria Vasquez Beltrão
}

\section{Resumo}

Apresenta-se aqui um "guia de visitação ao Geossítio Malacara - Praia Grande/SC", organizado em um aplicativo, disponível para aparelhos Smartphone com informações relativas à geodiversidade do atrativo, destinado à visitantes, guias e população em geral que tenham interesse em ter acesso às informações sobre a origem, constituição e características do atrativo. O material encontra-se disponível em uma versão digital de fácil acesso ao usuário, bastando apenas baixar o aplicativo para o celular. Este material poderá auxiliar os guias que realizam atividades no local, os visitantes e comunidade em geral, visando contribuir para o desenvolvimento do turismo e preservação do patrimônio geológico existente na região. $\bigcirc$ aplicativo encontra-se disponível através do link: http://app.vc/guia_de_visitacao_geossitio_malacara.

Palavras-chave: Geoturismo; Patrimônio Geológico; Geossítio Malacara; Praia Grande (SC)

\section{Abstract}

This is a "Visitation guide to Geosite Malacara - Praia Grande / SC", organized in an application, available for Smartphone devices with information on the geodiversity of the attraction, destined to visitors, guides and general population that have an interest To have access to information on the origin, constitution and characteristics of the attraction. The material is available in a digital version with easy access to the user, by simply downloading the application to the mobile phone. This material will be able to assist the guides who carry out on-site activities, visitors and the community in general, aiming to contribute to the development of tourism and preservation of the geological heritage in the region. The application is available through the link:

http://app.vc/guia_de_visitacao_geossitio_malacara.

Key-Words: Geoturism; geological heritage; Geoscite Malacara; Praia Grande (SC)

\footnotetext{
1 Tecnólogo em Gestão de Turismo pelo Instituto Federal Catarinense Campos Avançado Sombrio IFC - SC. Email: marlon3674@hotmail. com.

2 Licenciada e Bacharel em Geografia (UNESP), Especialista, Mestre e Doutora em Geografia (UFSC).Docente do Curso Superior de Tecnologia em Gestão de Turismo do Instituto Federal Catarinense, Campus Avançado Sombrio. E-mail: leila.beltrao@ifc.edu.br.
} 


\section{Introdução}

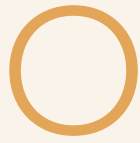

município de Praia Grande (SC) possui uma localização privilegiada, dispondo de ambientes de grande importância geológica. Geralmente os turistas ou excursionistas que procuram Praia Grande (SC) e região se deslocam visando o contato junto à natureza, realizando atividades como trilhas, rapel, escalada, canionismo, entre outros. Logo, o turismo de natureza transforma a própria geodiversidade em atrativo, pois o turista busca o contato com a paisagem composta pelas formas de relevo, hidrografia, flora e fauna. Contudo, se a experiência turística transcender a simples contemplação da paisagem e incluir a compreensão dos complexos processos envolvidos na interação entre esses elementos naturais, promove-se uma experiência turística mais significativa, bem como desperta-se um sentimento de cumplicidade com a preservação ambiental.

A região conta com duas unidades de proteção integral: o Parque Nacional (Parna) de Aparados da Serra e o Parna da Serra Geral, constituindo uma rede de proteção ambiental e de reconhecimento governamental da importância geológica, geomorfológica, hidrológica e botânica dos limites entre o nordeste do Estado do Rio Grande do Sul e do extremo sul de Santa Catarina. O município de Praia Grande se destaca, neste contexto, por estar incluído no perímetro de ambos os parques e desenvolver atividades relativas ao geoturismo, entendido como atividade que evidencia a geodiversidade de uma região, como um segmento potencial de interesse turístico (CEARÁ, sd). Porém ainda é necessário desenvolver uma conscientização sobre a real importância desses locais por parte da comunidade, guias e visitantes. É neste contexto que se insere a iniciativa de desenvolvimento do guia de visitação para dispositivo móvel, tendo como área de aplicação - Geossítio Malacara, um dos principais atrativos de Praia Grande/SC.

Para Brilha (2005, p. 126) "a sociedade não é ainda suficientemente sensível às questões relativas ao Patrimônio Geológico". Esse comportamento precisa ser revisto e alternativas que sirvam de instrumento educativo e que contribuam com o acesso à informação, são imprescindíveis em uma área que deseja desenvolver uma atividade turística que vise a sustentabilidade.

Neste contexto, é importante acrescentar que Praia Grande está incluída nos esforços da região para constituição do Geoparque "Caminhos dos Cânions do Sul", com a apresentação de candidatura ao reconhecimento da Unesco e da Rede Global de Geoparques (GGN), como território voltado às práticas de geoconservação, educação ambiental e desenvolvimento econômico sustentável, inserido em áreas de sítios geológicos de importância científica, raridade e beleza (UNESCO, 2014). Assim, iniciativas como estão desenvolvimento do aplicativo, contribuem no sentido de constituir-se em um projeto experimental que pode ser aperfeiçoado e estendido aos demais geossítios da região, contribuindo para que a estratégia territorial proposta pelo modelo "Geoparque" torne-se efetiva.

\section{Fundamentação teórica}

O turismo é visto por Goulart \& Santos (1998) como um fenômeno complexo, abrangente e que envolve não apenas aspectos econômicos, mas contribui diretamente nos aspectos sociais e nos valores culturais da sociedade, relacionando-se direta e indiretamente com os aspectos econômicos, sociais, culturais e ecológicos de uma determinada região. Ao relacionar-se, o turismo impacta de maneira positiva e/ou negativa. Essa relação é caracterizada por Beni (2008, p. 55) como um "confronto de forças, as humanas contra as físicas e ambientais".

Consoante com a ideia de que a ação humana sobre o meio ambiente acaba alterando os aspectos sociais, econômicos, culturais e ecológicos, "é preciso que o turismo e o meio ambiente encontrem um ponto de equilíbrio, a fim de que a atratividade dos recursos naturais não seja a causa de sua degradação" (RUSCHMANN, 2012).

Neste contexto Kundlatsch; Moreira (2016) descrevem que uma das formas de as pessoas adquirirem consciência sobre a necessidade de fomentar o equilíbrio na relação com os recursos se dá por meio da educação ambiental, e que o 
grande desafio é estimular mudanças de atitude e comportamento nas populações. Consoante com esta ideia, Brilha (2005, p. 11) aponta que "é cada vez mais urgente conscientizar o cidadão do lugar que ocupa na bio e na geodiversidade e do modo como melhor se articular com elas, no respeito pelo equilíbrio ambiental". Assim Moreira (2008, p. 79) ressalta que "é importante que a Terra seja entendida e interpretada como um todo, tanto pelos seus aspectos de biodiversidade, quanto de geodiversidade"

A geodiversidade é compreendida por Araújo (2005, apud Moreira, 2008, p. 56) como "o conjunto de elementos geológicos e geomorfológicos da paisagem". Tal conceito, apesar de aparentemente simples, é dotado de grande complexidade, pois engloba "uma multiplicidade de fatores e da relação entre eles" (BRILHA, 2005 p. 25).

O turismo utiliza espaços naturais que possuem relevância geológica sobretudo nas práticas de turismo de natureza ou ecoturismo (CRUZ, 2003). Essas práticas de Turismo passaram a se popularizar a partir dos anos de 1990, quando o ecoturismo surgiu como uma atividade não predatória, potencialmente capaz de ser uma alternativa para geração de renda para comunidades (PIRES, 2008).

Juntamente com o turismo em áreas naturais,

"[...] um novo segmento turístico denominado de geoturismo passou a ser divulgado mundialmente, tendo como seus atrativos os aspectos abióticos da paisagem, muitas vezes negligenciados pelo ecoturismo e pelos programas de conservação da natureza" (BENTO; RODRIGUES, 2010, p. 55).

Para Moreira (2008) este segmento turístico está relacionado com a necessidade de entendimento das áreas visitadas por parte dos turistas e com a possibilidade de divulgação e valorização de aspectos representativos da história geológica da Terra, bem como sua evolução geomorfológica. Tais áreas constituem-se no patrimônio geológico.

Para MOREIRA (2008 p. 243) este patrimônio é constituído por um conjunto de recursos naturais não renováveis que tendo um valor científico, cultural ou educativo, permite conhecer, estudar e interpretar a história geológica da Terra, bem como os processos que a modelaram e continuam modelando.

Tal conceito, não exclui a sociedade dos frutos decorrentes da atividade turística baseada na exploração do patrimônio geológico. Ao contrário, visa introduzir o princípio de que o respeito ao patrimônio e o turismo ambiental e socialmente responsável são compatíveis, e que a divulgação da importância do patrimônio geológico deve servir como alavanca para o desenvolvimento e a sustentabilidade da população local.

Ruchkys (2009) destaca que interpretação do patrimônio geológico deve apresentar a informação em um nível de compreensão apropriado ao público, e deve envolver e fascinar, indicando a importância daquele patrimônio e de sua conservação.

Brilha, por sua vez, complementa indicando que

para transmitir uma determinada mensagem é necessário que o destinatário se interesse por ela. Daí a captação da atenção do público alvo deve ser a primeira preocupação de quem planeia uma ação de interpretação. A mesma deve ser agradável e relevante para o destinatário, devendo procurar-se estabelecer relações entre o quotidiano e os conhecimentos do cidadão comum (BRILHA, 2005, p. 110).

Concordando com as definições ressaltadas, a interpretação do patrimônio geológico necessita apresentar a informação de forma envolvente e fascinante para o público. Além disto, deve apresentar-se de maneira atrativa e consoante com as tecnologias que se usam na atualidade. Daí a necessidade de traduzir os conhecimentos geológicos para uma ferramenta ágil, aliando uso da tecnologia da informação com a educação ambiental. Tem-se então um elo prático entre os princípios da geoconservação a sociedade atual e seus hábitos.

Com os avanços tecnológicos cada vez mais 
evidentes no cotidiano da sociedade, denota-se uma mudança das atuais gerações em sua relação com o uso da tecnologia da informação e comunicação (TIC). Tal relação para Rodrigues; Colesanti, (2008) impacta na compreensão de mundo, no modo de representá-lo, e geralmente vem acompanhada por uma série de mudanças culturais, presentes no cotidiano, seja no espaço de trabalho, de lazer e/ou de ensino. Tais autores ressaltam ainda que "a educação, de fato, sempre se constituiu em um processo de comunicação. Desde tempos remotos da nossa civilização, a educação, a informação e a comunicação sempre caminharam juntas" (idem, 2008, p.64) Sob essa perspectiva, o uso da tecnologia pode contribuir diretamente no desenvolvimento de um meio de comunicação que seja eficaz e atraente ao público receptor.

Nesse caso, o uso das novas tecnologias de comunicação com enfoque na Educação Ambiental representa um avanço, já que por meio da integração da informática e dos multimeios pode haver a sensibilização e o conhecimento dos ambientes e dos seus problemas intrínsecos. A virtualidade nesse sentido pode representar um novo esforço na construção e incorporação de conhecimentos ambientais por meio de estratégias mais atrativas de comunicação (RODRIGUES; COLESANTI, 2008, p. 64)

Acordando com a ideia dos autores o projeto enfatiza, por meio de uma ferramenta tecnológica, ou seja, um aplicativo móvel para aparelhos smartphone, a geodiversidade, evidenciando e contextualizando os aspectos geológicos, geomorfológicos e hidrológicos de um geossítio do município de Praia Grande (SC).

\section{Materiais e métodos}

A pesquisa para Marconi; Lakatos (2010 p. 01) "é um procedimento formal, com método de pensamento reflexivo, que requer um tratamento científico e se constitui no caminho para se conhecer a realidade ou para descobrir novas verdades".
Tendo como ponto de partida tal pressuposto, o projeto estruturou-se em um conjunto de procedimentos sistemáticos onde, a abordagem teórica, serviu como subsídio para que a leitura da realidade observada pudesse ser interpretada a luz de um conjunto de raciocínios e conceitos lógicos, possibilitando uma proposta de intervenção no real que contribua para atingir o objetivo maior: divulgar e fomentar a importância da geodiversidade no geossítio Malacara - Praia Grande/SC.

A pesquisa secundária contou com o apoio bibliográfico foi baseado em artigos, livros, monografias e dissertações de autores que desenvolvem trabalhos voltados a temas que coincidem com a proposta de ação. Lançou-se mão também de informações coletadas em sites de órgãos oficiais ligados ao desenvolvimento do turismo, educação, preservação do meio ambiente e patrimônio geológico, bem como informações disponibilizadas pelo setor turístico municipal, entre outros.

A pesquisa primária envolveu trabalhos de campo visando o monitoramento da trilha de acesso e o reconhecimento e registro dos aspectos geológicos do atrativo que foram posteriormente inseridos no aplicativo. Adicionalmente, acompanhou-se guias credenciados do Parna Serra Geral na condução de grupos de turistas, com o intuito de compreender como as atividades turísticas são desenvolvidas no geossítio Malacara, a percepção dos visitantes perante ao atrativo e a atuação dos guias no processo de condução no que se refere às informações sobre o patrimônio geológico.

\section{A geodiversidade do parque nacional da serra geral e do geossítio malacara}

O geossítio Malacara está inserido no território do Parque Nacional (Parna) da Serra Geral (Figura 01), criado pelo Decreto $n^{\circ} 531$, de 20 de maio de 1992, com área de 17.300 hectares. Além do geossítio citado, as trilhas do Mirante do Fortaleza, da Pedra do Segredo e da Borda dos Cânions são outras atrações do Parque (BRASIL, 2016). 
Figura 01 - Visão aérea do Parque Nacional da Serra Geral

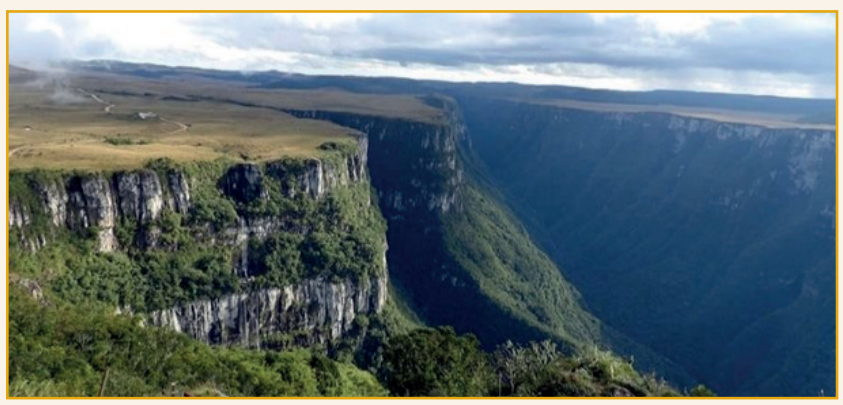

Fonte: Sociedade Pública, 2016.

Segundo o controle de visitação do Parque, o local recebe uma média anual de32.500 turistas, configurando junto com o Parque Nacional Aparados da Serra, o maior produto turístico da região (LIMA; VARGAS; PIMENTA, 2014).

A região onde hoje está instalado o Parna Serra Geral (bem como o Parna Aparados da Serra), possui aspectos de grande importância na história evolutiva da Terra, pois abriga representativas evidências do passado geológico e geomorfológico do planeta, percebidas através de uma observação das características do relevo do território. Contudo, quais são tais elementos? Quais processos que explicam os cenários presentes no geossítio Malacara e região?

\section{A origem geológica da região}

A região do geossítio Malacara é parcela do grande 'Planalto Arenito-basáltico' onde, entre 152 e 145 milhões anos atrás, havia um ambiente desértico, com a presença de ventos que transportavam a areia e formavam grandes dunas (ROSA; ROCHA, 2009). No período, a América do Sul ainda estava conectada ao continente africano, Antártida, Índia e Oceania (Figura 02 ao lado), formando o pretérito continente de Gondwana,

Sob condições de um paleoclima seco e quente, o gigantesco deserto deu, em sua evolução, origem aos arenitos, produto da diagênese 3

3 Diagênese ou cimentação é o processo de agregação de grãos ou fragmentos de rocha através da ação de um cimento
Figura 02 - Laurásia e Gondwana no Jurássico Superior, era Mesozóica

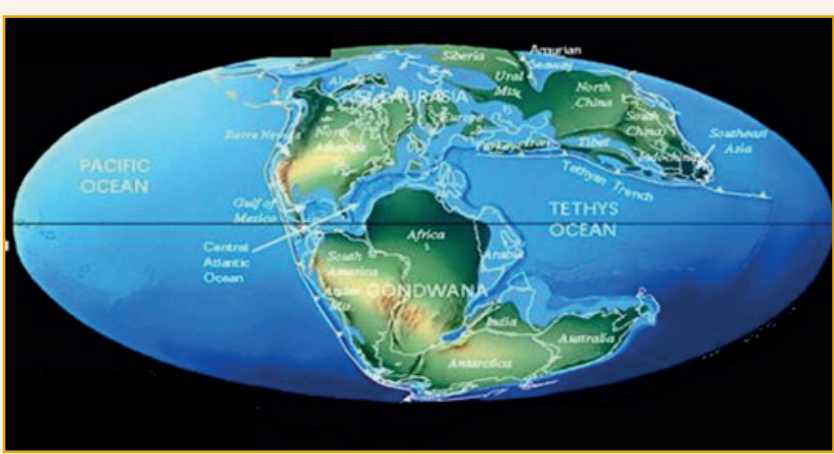

Fonte: Scotese, 2003

na areia, formando depósitos porosos e permeáveis (MAACK, 2001). Entre o Brasil, Argentina, Paraguai e Uruguai, tal deserto deu origem à Bacia Sedimentar do Paraná, com 1,5 milhão de quilômetros quadrados, estendendo-se também pelo continente africano, no planalto de Etendeka, na Namíbia, com 78 mil quilômetros quadrados (MILANI et all., 2007). Os agentes externos de relevo eram os principais atuantes naquele momento

$\mathrm{Na}$ continuação do processo, contudo, se adicionaram forças internas, através da ação de movimentos tectônicos, responsáveis pela abertura do Oceano Atlântico, através da formação da grande cadeia mesoatlântica. Tal movimentação deu origem a diversos falhamentos e fraturas, por onde houve saída de lava através de vulcanismos fissurais. Neste ambiente, imensos falhamentos foram abertos pela movimentação do terreno. Destes falhamentos, de tempos em tempos, saíam grande quantidade de lavas vulcânicas, que se espalhavam em direção a oeste. Quando estas erupções cessavam, as lavas resfriavam e solidificavam, formando as rochas denominadas basaltos, que eram recobertas pelas areias do deserto. O planalto ficou composto por camadas de arenito (mais friáveis), alternadas com camadas de basalto (mais resistente). (ROSA; ROCHA, 2009, p. 09).

de natureza silicosa, argilosa, calcária ou ferruginosa (GUERRA, 1980, p. 94). No caso em questão foi o processo responsável pela transformação dos depósitos de areia em rocha arenítica. 
A extensão desses derramamentos chegou a 1,2 milhão de quilômetros quadrados na Bacia do Paraná, extravasados em cerca de 10 milhões de anos, com clímax entre 133 e 129 milhões de anos atrás (MILANI et al., 2007). No continente africano, por sua vez, a extensão dos derramamentos foi menor, não ultrapassando um total de 106 mil quilômetros quadrados. Assim,

estas áreas apresentam características geológicas semelhantes nos dois continentes, sendo um dos argumentos utilizados como indicador da presença de um continente único, existente antes da abertura do Oceano Atlântico e da deriva continental.(WILDNER; ORLANDI FILHO; GIFFONI, sd, p.161).

Toda a movimentação tectônica envolvida na abertura do oceano Atlântico e o extravasamento de milhões de toneladas de material magmático, alterou o equilíbrio das placas. Assim, no centro da grande bacia do Paraná "o peso do grande derrame eruptivo" gerou uma "depressão que teve como efeito, o soerguimento da borda oriental do continente" (MAACK,2001,p. 206), como resposta à busca do equilíbrio isostático ${ }^{4}$. Tal movimentação explica o corte abrupto da Serra Geral que representa uma escarpa de borda de planalto. Tal levantamento processou-se, provavelmente, a partir do final do Cretáceo e ao longo de todo o Terciário, produzindo desnivelamentos superiores a 1.000 metros" (GODOY; BINOTTO; WILDNER, 2011).

Tal corte, cuja orientação das camadas mergulha para oeste, recebe o nome de "cuestas" e faz a transição entre o planalto propriamente dito e a área rebaixada, denominada depressão periférica. A Figura 03 mostra um bloco diagrama do Planalto Meridional.

4 Segundo Guerra (1980, p. 239), a isostasia é a condição de equilíbrio que se realiza entre a crosta continental (menos densa, formada predominantemente de silício e alumínio) que flutua sobre crosta oceânica (mais densa, formada de silício e magnésio). A alteração no peso aplicado sobre a placa continental (como o ocorrido no centro da Bacia do Paraná, com o derramamento de material vulcânico) gera um afundamento da placa continental. Como resposta e em decorrência da necessidade em manter o equilíbrio, a borda leste da placa continental sofreu um soerguimento.
Figura 03 - Representação do Planalto Meridional

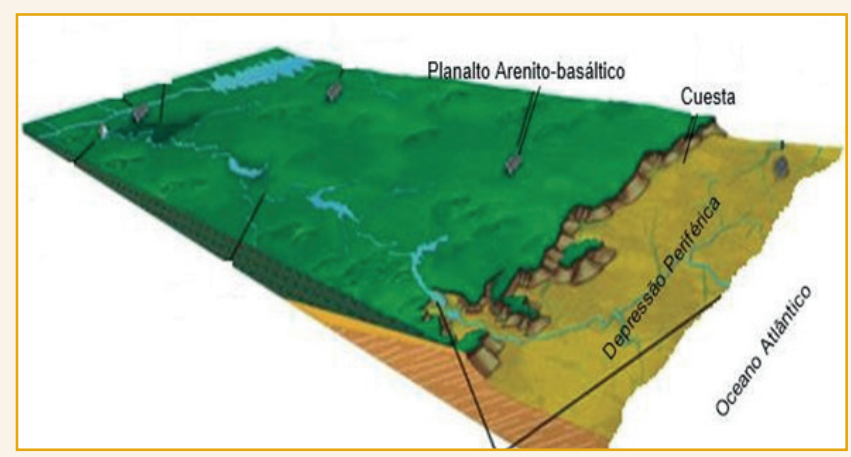

Fonte: Adaptado de Beltrão; Dalpiaz, 2016.

Consoante, Oliveira (2014, p.50) indica que "geologicamente, esse trecho do litoral brasileiro resgata a história dos eventos tectônicos distensivos que marcaram o processo de abertura do Oceano Atlântico e de separação dos continentes sul-americano e africano".

Esta fragmentação foi acompanhada de um amplo soerguimento de toda a borda leste do recém-criado continente da América do Sul e da borda sudoeste da África, fazendo com que o conjunto de derrames vulcânicos, e as rochas colocadas abaixo, fossem soerguidas topograficamente, formando o que posteriormente denominou-se de Serra Geral e Serra do Mar, no continente sul americano (GODOY; BINOTTO; WILDNER, 2011 p.18).

Soerguida a borda de escarpa, teve início o processo de erosão. A ação dos agentes externos, sobretudo o trabalho dos rios tem esculpido, ao longo do tempo geológico o paredão da encosta, formando verdadeiras gargantas. Estas formam os cânions.

\section{A formação dos cânions}

A escarpa da Serra Geral possui como característica diversos recortes em sua formação, produzidas pelo constante trabalho erosivo das redes de drenagem que esculpem profundos vales em "V". A escarpa da Serra Geral evidencia todo o processo de fragmentação do supercontinente 
Gondwana, e possui grande valor geológico. Os cânions, são definidos pelo Serviçp Geológico do Brasil como "desfiladeiros ou vale profundos, estreito e longo, com paredes verticalizadas, cortando altiplanos ou regiões montanhosas, e em cujo talvegue normalmente flui a drenagem" (BRASIL, 2016, sp.). Outra forma de definir cânion é caracterizá-lo como desfiladeiro que, morfologicamente, é análogo à garganta, mas com a diferença de extensão; um desfiladeiro pode ter extensão de quilômetros, enquanto que uma garganta corresponde a um vale com paredes abruptas que corta uma crista ou uma faixa montanhosa de pequena largura (idem, 2016).

O fator de desenvolvimento dos cânions na escarpa da Serra Geral é a presença de fraturas e falhas nas rochas vulcânicas. Tais falhas e fraturas resultantes dos esforços tectônicos e dos processos de resfriamento do material, constituem-se em zonas de fraqueza, onde a percolação da água é mais intensa (SCHMIGUEL; VARGAS \& TRATZ, 2009). Os mesmos autores destacam que

Os falhamentos gerados durante o evento e registrados na área são do tipo escalonado sendo responsável pela existência da escarpa original em diversas cotas topográficas da plataforma atlântica e orientando alguns canais, sub- bacias e gargantas ocupadas por rios. (idem, p. 04)

O Malacara, como geossítio, guarda então essa importância geológica: ele é definido como um cânion, o rio Malacara e seus afluentes de primeira e segunda ordem, são os principais responsáveis pelo entalhamento das encostas, como observado na figura 04 (ao lado). Assim, o geosssítio Malacara constitui-se em patrimônio geológico porque retrata não só os processos internos como os externos de formação da América do Sul a partir da era Mesozóica.

\section{Diferenciação dos derrames}

Os derrames, que se sucederam ao longo de 10 milhões de anos, atingiram pacotes de centenas de metros de espessura. Leinz \& Amaral (1989,
Figura 04 - Cânion Malacara visto do leito do rio Malacara

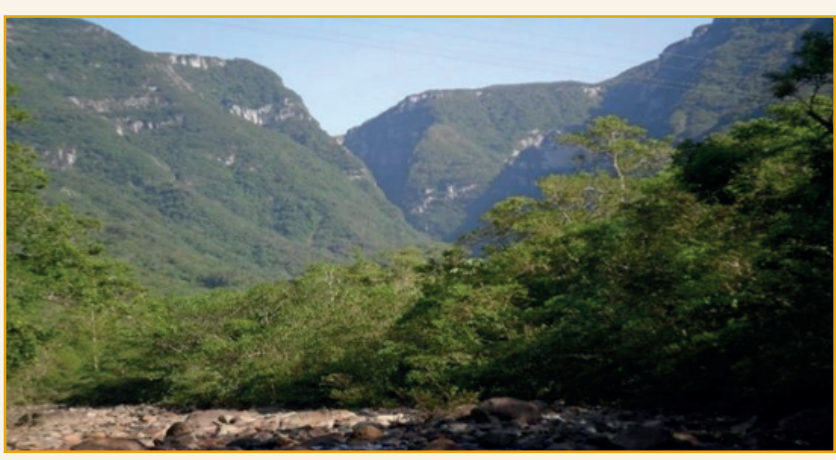

Fonte: Os Autores, 2016

p. 286) descrevem que "na escarpa do sul de Santa Catarina, podem ser individualizados 25 derrames, pelo reconhecimento das zonas de vesículas, tendo o primeiro deles, o da base, uma espessura de 90 metros". Como apontam Wildner; Orlandi Filho \& Giffoni (sd. p. 07), a melhor visualização dos empilhamentos é dada no cânion Fortaleza, onde é possível contabilizar 13 derrames aflorantes.

Tal sucessão não é tão perceptível no cânion Malacara, porém a compreensão de como se pode distinguir os derrames, já é o suficiente para ter noção da complexidade envolvida no processo de resfriamento. A figura cinco apresenta uma montagem onde as marcas dos diferentes derrames estão destacadas.

Figura 05 - Paredes do cânion Malacara a partir dos campos de cima da serra

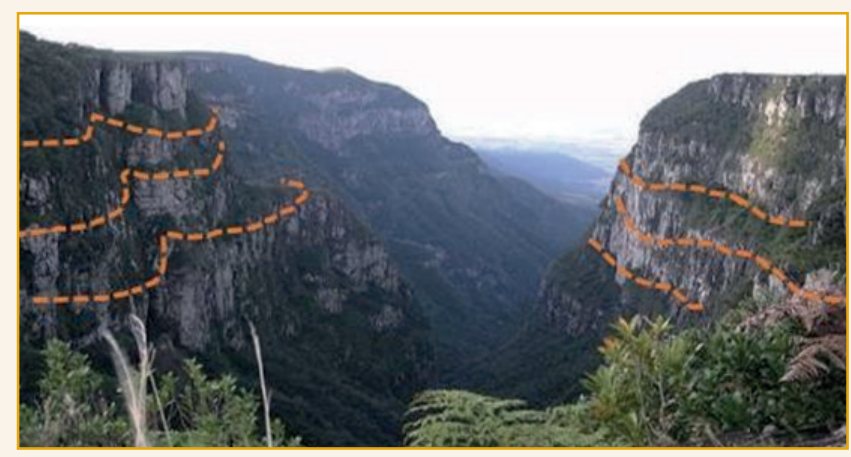

Fonte: Adaptado pelo autor a partir de AZEVEDO, 2010

Na paisagem, como mostra a figura cinco, pode-se distinguir os derrames de lava vulcânica a partir da existência de faixas horizontais onde desenvolvem-se cordões de vegetação. Trata-se de 
pequenos patamares ou degraus, onde as condições são propícias ao desenvolvimento vegetal, incluindo exemplares de grande porte, como a araucária (Araucaria angustifolia). Leinz \& Amaral
(1989) descrevem a constituição textural de cada derrame. Apesar dos estágios não serem visíveis em sua totalidade na imagem anterior, cada derrame, normalmente, varia da seguinte forma:

Quadro 01 - Constituição Textural dos Derrames Magmáticos da Serra Geral 1. BASE: Constituição vítrea, graças ao rápido resfriamento da lava em contato com o substrato frio, gerando o basalto vítreo, onde a
infiltração da água é mais difícil.

2. DIÁCLASES HORIZONTAIS: presença de um basalto microcristalino onde as diáclases (linhas de fratura) apontam que os gases descreveram uma trajetória horizontal durante o processo de resfriamento. A estrutura microcristalina permite maior retenção de água, dando origem a fontes de água e gerando condições para desenvolvimento vegetal, daí as "faixas verdes" que podem ser facilmente visualizadas na encosta.

3. DIÁCLASES VERTICAIS: a parte mais espessa do derrame, é constituída de um basalto de granulação mais grosseira, onde predominam as diáclases verticais. Tais linhas de fratura facilitam a infiltração de água gerando uma erosão que reforça a escarpa.

4. TOPO: é uma faixa onde houve maior acúmulo de gases, aprisionados pelo resfriamento. Formaram vesículas ocas ou preenchidas, geralmente por quartzo pouco ou bem desenvolvido.

Fonte: elaborado com base em Leinz \& Amaral (1989, p. 289-290).

A representação dos derrames pode ser assim esquematizada:

Figura 06 - Diagrama com o esquema do derrame basáltico

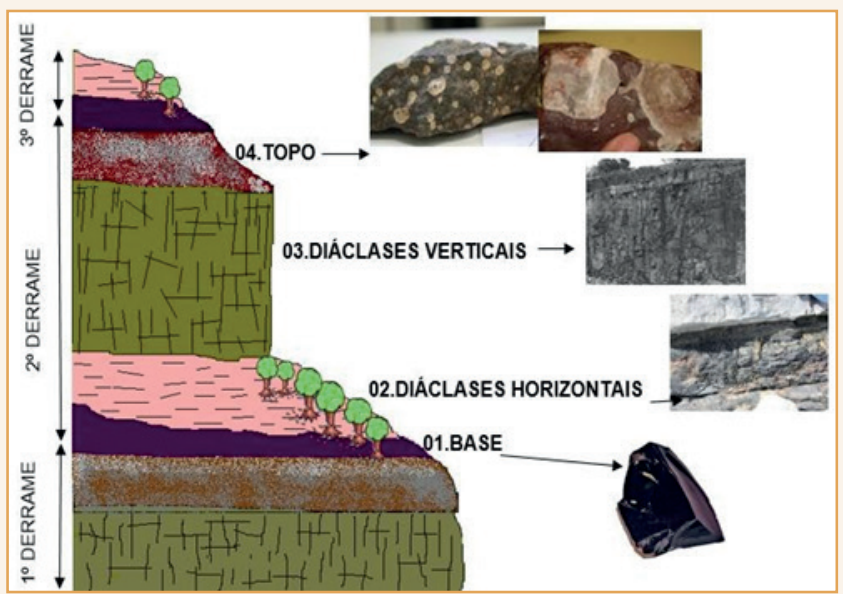

Fonte: Elaborado pelo autor com base em Leinz; Amaral (1989, p. 290)

Para o visitante que percorre a trilha de acesso ao cânion Malacara, os aspectos que mais se destacam na paisagem são as diáclases verticais, pois formam espessos paredões, a vegetação que recobre as diaclases horizontais. Contudo, os fragmentos da base e do topo são encontrados em grande número no leito do rio Malacara, após te- rem sido trabalhados pela erosão.

\section{O leito do Malacara e os sedimentos}

O geossítio pode ser acessado a partir do vale do cânion, através do curso do rio Malacara a partir da comunidade de Vila Rosa - Praia Grande- SC.

Figura 06 - Seixos rolados trilha do Cânion Malacara

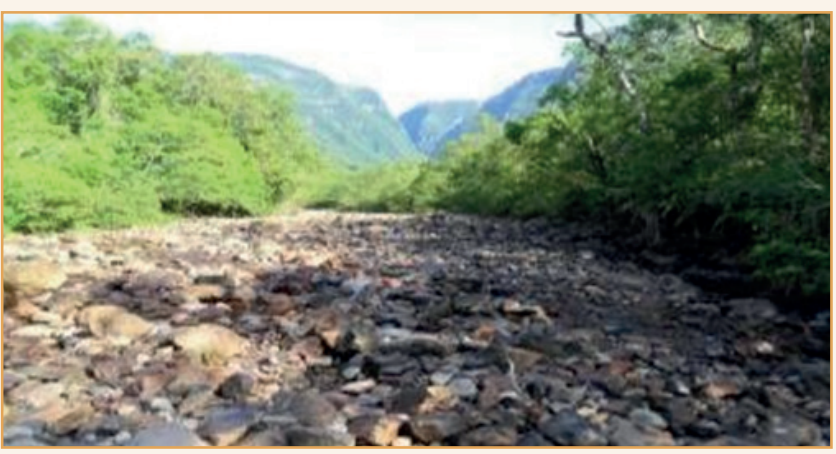

Fonte: Os Autores, 2016

É possível observar através do percurso da triIha, que as rochas se encontram arredondadas (figura 06), em decorrência dos processos hídricos que transportam o material erodido. $\bigcirc$ material 
transportado e acumulado no leito do rio faz com que, sobretudo nos momentos de grandes enxurradas, as águas transbordem o leito normal e passem a construir novos caminhos, alterando comumente o percurso para novos traçados.

Todos estes aspectos fazem do Parna Serra Geral e do Geossítio Cânion Malacara, áreas que merecem respeito e preservação, e acima de tudo a compreensão da sociedade sobre sua relevância. A divulgação desse atrativo e seu uso de maneira sustentável, pode contribuir para a preservação deste local, e também para o desenvolvimento de um sentimento de pertencimento da sociedade frente ao patrimônio geológico.

\section{Descrição do aplicativo}

O aplicativo móvel (figura 07) que foi desenvolvido, tem o intuito de divulgar o Cânion Malacara como um atrativo turístico e apresentar as características principais que o fazem importante para o planeta e para a humanidade. Busca também, a partir de uma interação entre a sociedade e as informações contidas no aplicativo, um aumento no interesse de possíveis visitantes e comunidade local em conhecer o Gessítio Malacara, e contribuir para preservação do mesmo. $\bigcirc$ aplicativo contém informações que também poderão auxiliar guias e operadores que desenvolvem atividades no atrativo, complementando o conhecimento sobre o local. Ele pode ser acessado no endereço: http://app.vc/guia_de_visitacao_geossitio_malacara

Figura 07 - Layout do aplicativo

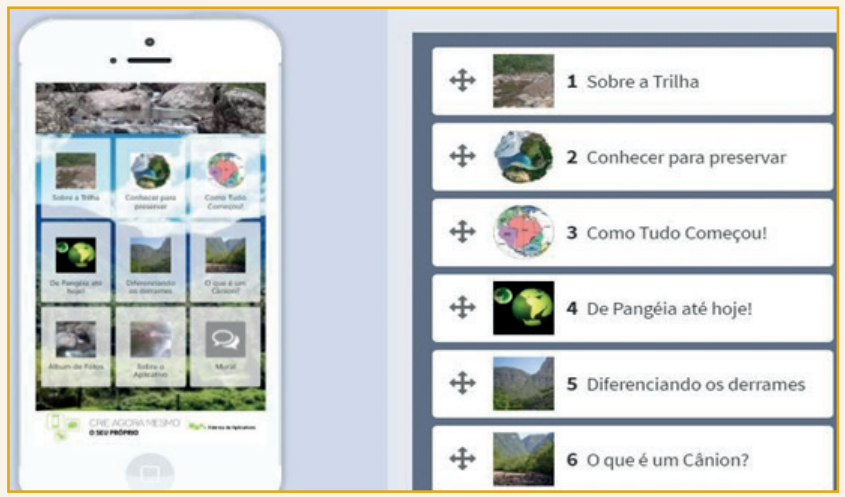

Fonte: Os Autores, 2016.
Oplicativo foi desenvolvido pelo site "Fábrica de Aplicativos", e está disponível de forma gratuita para aparelhos smartphone com sistema operacional Android. O mesmo conta com oito abas informativas que dispõem de conteúdo informativo e servem como instrumento de divulgação do atrativo turístico, e também como um guia digital, informando sobre o que há no atrativo a ser visitado.

\section{Divisão do aplicativo}

O aplicativo atualmente está dividido em nove abas, com informações pertinentes ao Geossítio Malacara visandoinformar de forma clara, didática e atrativa seu conteúdo, de modo que o usuário tenha interesse pelas informações.

Assim, o instrumento contribui não apenas para divulgação do geossítio e região e como serve como um guia digital, podendo ser considerado um instrumento para o fomento da educação ambiental e preservação do atrativo. $\bigcirc$ quadro a seguir apresenta as telas do aplicativo, com o respectivo conteúdo abordado:

A figura 08 apresenta algumas das telas desenvolvidas no aplicativo:

Figura 08 - Divisão de telas do aplicativo

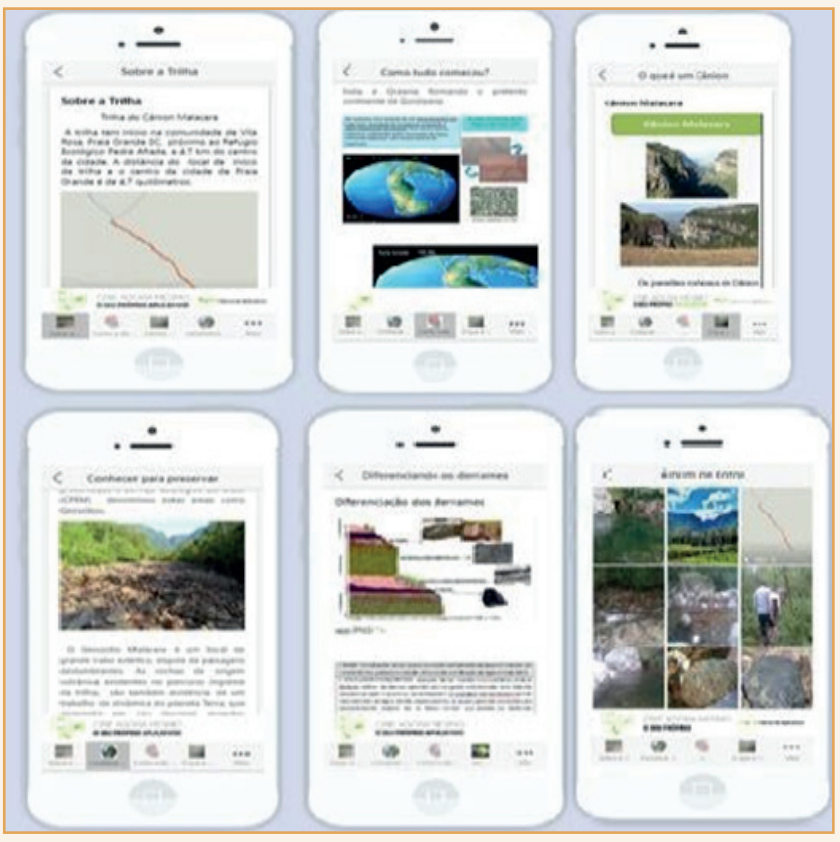

Fonte: Os Autores 2016. 
Quadro 02 - Divisão do aplicativo

\begin{tabular}{|c|c|}
\hline Título de Tela & Conteúdo \\
\hline Sobre a trilha & $\begin{array}{l}\text { Informações úteis sobre condições de execução da atividade como: extensão, } \\
\text { duração da trilha, o que vestir e levar. }\end{array}$ \\
\hline Conhecer para preservar & $\begin{array}{l}\text { Visa sensibilizar o usuário da ferramenta sobre a importância da preservação } \\
\text { do atrativo, apresentando sua importância enquanto patrimônio geológico da } \\
\text { humanidade. }\end{array}$ \\
\hline Como tudo começou & $\begin{array}{l}\text { Material didático explicativo sobre os processos geológicos pretéritos que } \\
\text { formaram o geossítio e região. }\end{array}$ \\
\hline De Pangeia até hoje & Vídeo que ilustra o processo de separação dos continentes. \\
\hline Diferenciando derrames & $\begin{array}{l}\text { Informa, de forma resumida como se estratificaram os derrames vulcânicos e como } \\
\text { visitante pode observar as diferenciações na paisagem. }\end{array}$ \\
\hline O que é um cânion? & Informa como se formaram os cânions da região. \\
\hline Álbum de fotos & Acervo de imagens coletadas no geossítio Malacara. \\
\hline Mural & Local onde o visitante poderá dar sua opinião ou sugestão, \\
\hline Sobre o aplicativo & Informações sobre o motivo da elaboração de tal ferramenta. \\
\hline
\end{tabular}

Fonte: Os Autores 2018.

\section{Resultados alcançados}

Este aplicativo foi pré-programado pela Fábrica de Aplicativos. Nele foram acrescentadas as informações e imagens, pertinentes à geodiversidade da região, com informações específicas de um atrativo que recebe considerável número de visitantes no extremo sul de Santa Catarina: o geossítio Malacara. A ideia foi disponibilizar informação acessível e ampla para sociedade, em um meio de comunicação atual. $\bigcirc$ aplicativo serve como uma ferramenta de apoio, onde o visitante, guia ou qualquer interessado em conhecer um pouco sobre o geossítio Malacara possa acessar informações de maneira clara e objetiva.

O aplicativo móvel evidencia as características pertinentes à geodiversidade e a importância do patrimônio geológico regional, contribuindo, para a melhoria da percepção dos visitantes e interessados sobre os complexos processos envolvidos na formação da paisagem. Com esta iniciativa espera-se contribuir para o desenvolvimento do Geoturismo na região.

\section{Conclusão}

A presente produção buscou a compreensão dos principais aspectos geológicos da região do Parna Serra Geral e do Geossítio Malacara, considerando a importância dos mesmos para o desenvolvimento do turismo. Assim, buscou-se propor uma alternativa para preservação do patrimônio geológico através da divulgação do processo de constituição de alguns elementos da geodiversidade. Isso porque partiu-se da premissa que o conhecimento é um elemento fundamental para o desenvolvimento da consciência preservacionista. Por tal, a presente proposta é também uma iniciativa de educação ambiental, que visa contribuir para o desenvolvimento de uma atividade turística sustentável.

A veiculação da informação através de meios de comunicação ágeis e de fácil acesso se constituem em uma ferramenta que pode contribuir de forma efetiva para preservação e divulgação do patrimônio, auxiliando na compreensão, por parte da sociedade, sobre a importância dos atrativos turísticos. Pode ainda desenvolver, na comunidade do entorno, o sentimento de pertencimento, 
incentivando o engajamento na luta pela preservação e exploração sustentável do patrimônio.

A geodiversidade é um elemento de grande relevância para o turismo na cidade de Praia Grande (SC) e região. Desta forma, salvaguardá-la é uma forma de manter a identidade de elementos que representam muito para compreensão humanidade sobre um importante processo evolutivo da Terra. Neste contexto, a elaboração deste trabalho buscou enfatizar este tema e a partir da disseminação de informações compreensíveis para leigos, contribuindo para o entendimento de que tais elementos são de grande importância e precisam ser conhecidos e preservados.

A elaboração do presente guia, disponível em meio eletrônico, surge como uma alternativa para alcançar a sociedade, adequando-se aos hábitos contemporâneos. A disseminação da informação pode ser fundamentalmente importante no processo de interação da sociedade com a temática do turismo sustentável. A geodiversidade evidentemente é de grande importância não apenas como um produto de uso exploratório, mas também como um registro fundamental para a compreensão da humanidade sobre o planeta onde vive. Deste modo deixa-se em aberto o aprimoramento desta iniciativa, e a partir da mesma, abre-se a possibilidade da elaboração de material semelhante para os demais atrativos da região. 


\section{Referências}

AZEVEDO, Beatriz. Outras cachoeiras do Malacara. In: Alta Montanha, 2010. Disponível em: http:// altamontanha.com/Aventura/2587/outras-cachoeiras-do-malacara. Acessado em 27 nov, 2016.

BELTRÃO, Leila Maria Vasquez; DALPIAZ, Maurício. Curso de capacitação de profissionais de turismo e docentes de Educação Básica. Sombrio: IFC, 2015. 48 slides, color.

BENI, Mario Carlos. Análise estrutural do turismo. 13. ed. São Paulo: Senac, 2008. 556 p.

BENTO, Lilian Carla Moreira; RODRIGUES, Sílvio Carlos. O geoturismo como instrumento em prol da divulgação, valorização e conservação do patrimônio natural abiótico: uma reflexão teórica. Turismo e Paisagens. Campinas, v. 3, n. 2, p.55-65, dez. 2010.

BRASIL, Serviço Geológico do Brasil. Ministério do Meio Ambiente. Geodiversidade. sd. Dispobnível em: <http://www.cprm.gov.br/publique/Gestao-Territorial/Geodiversidade-162>. Acesso em: 26 out. 2016.

BRASIL. Comissão Brasileira de Sítios Geológicos e Paleobiológicos. Geossítios. 2016. Disponível em: http:// sigep.cprm.gov.br. Acesso em: 01 nov. 2016.

BRASIL. Comissão Brasileira de Sítios Geológicos e Paleobiológicos. Ministério de Minas e Energia. O que é um sítio geológico? 1999. Disponível em: <http://sigep.cprm.gov.br/apresenta.htm>. Acesso em: 24 out. 2016.

BRASIL. Instituto Chico Mendes de Conservação da Biodiversidade. Ministério do Meio Ambiente. Unidades de Conservação. 2016. Disponível em: <http://www.icmbio.gov.br/portal/unidades-de-conservacao>. Acesso em: 26 set. 2016.

BRASIL. Ministério do Meio Ambiente. Ministério do Meio Ambiente. Educação Ambiental. 1999. Disponível em: <http://www.mma.gov.br/educacao-ambiental>. Acesso em: 03 out. 2016.

BRILHA, José. Patrimônio Geológico e Geoconservação: A conservação da natureza e sua vertente geológica. Braga: Palimage, 2005. $186 \mathrm{p}$.

CEARÁ. Coordenação Executiva do Geopark Araripe. Secretaria das Cidades. Geopark Araripe: histórias da terra, do meio ambiente e da cultura. Fortaleza: S.e, . 167 p.

CRUZ, Rita de Cássia Ariza da. Políticas públicas de turismo no Brasil: território usado, território negligenciado. Geosul, Florianópolis, v. 20, n. 40, p.27-43, 2005.

GODOY, Michel Marques; BINOTTO, Raquel Barros; WILDNER,

Wilson. Geoparque Caminhos dos Cânions do Sul: Proposta. Brasília: Serviço Geológico da Brasil, 2011. 109 p.

GUERRA, Antônio Teixeira. Dicionário geológico-geomorfológico. 6ªed. Rio de Janeiro: IBGE, 1980.

KUNDLATSCH, César Augusto; MOREIRA, Jasmine Cardozo. Painéis interpretativos: ferramentas de educação ambiental no turismo em áreas naturais. Caderno de Estudos e Pesquisas em Turismo, Curitiba, v. 5, n. 7, p.3450, jul. 2016. Semestral.

LEINZ, Viktor; AMARAL, Sérgio Estanislau do. Geologia Geral. 11ed. São Paulo: Editora Nacional, 1989.

LIMA, Flavia Fernanda de; VARGAS, Jean Carlos; BRILHA, José. Geoconservação, geoturismo e geoparques.

Florianópolis: Universidade Federal de Santa Catarina, 2014. 53p. 
LIMA, Flavia Fernanda de; VARGAS, Jean Carlos; PIMENTA, Luiz. Projeto geoparque Caminhos do Sul: Diagnóstico do território e Recomendações para Candidatura. Curitiba: Geodiversidade Soluções Geológicas, 2011. $190 \mathrm{p}$.

MAACK, Reinhard. Breves notícias sobre a geologia dos estados do Paraná e Santa Catarina. Brazilian Archives of Biology and Technology. Curitiba. Jubilee Volume (1946-2001): pp. 169 - 288, dez. 2001.

MARCONI, Marina de Andrade; LAKATOS, Eva Maria. Técnicas de Pesquisa: - Planejamento e execução de pesquisas - Amostragens e técnicas de Pesquisa - Elaboração, análise e interpretação de dados. 7. ed. São Paulo: Atlas, 2012. 277 p.

MILANI, Edison José; MELO, José Henrique; SOUZA, Paulo Alves de; FERNANDES, Luiz Alberto; FRANÇA, Almério Barros. Bacia do Paraná. Boletim de Geociências da Petrobrás. Rio de Janeiro, v.15, n.2, p. 265-287, mai./nov.2007.Semestral.

MOREIRA, Jasmine Cardozo. Patrimônio geológico em unidades de conservação: atividades interpretativas, educativas e geoturísticas. 2008. 429 f. Tese (Doutorado) - Curso de Geografia, Universidade Federal de Santa Catarina, Florianópolis, 2008. Cap. 5.

NASCIMENTO, Marcos Antonio Leite do. Diferentes ações a favor do patrimônio geológico brasileiro. Estudos Geológicos, Natal, v. 20, p.81-92, fev. 2010. Disponível em: <https://www.ufpe.br/estudosgeologicos/paginas/ edicoes/2010202/2010202t06.pdf>. Acesso em: 19 out. 2016.

OLIVEIRA, Antônio Pereira. Turismo e Desenvolvimento: Planejamento e Organização. 3. ed. São Paulo: Atlas, 2001. 225 p.

OLIVEIRA, José Carlos da Silva. Geoparques no Brasil: Foco Geográfico Na Superação Dos Desafios. 2014.124 f. TCC (Graduação) - Curso de Graduação em Geografia, Departamento de Geografia (gea), Universidade de Brasília, Brasília, 2014.

RODRIGUES, Gelze Serrat de Souza Campos; COLESANTI, Marlene T. de Muno. Educação ambiental e as novas tecnologias de informação e comunicação. Sociedade \& Natureza, Uberlândia, v. 20, n. 1, p.51-66, jun. 2008.

Disponível em: <file://C:/Users/User/Desktop/Estágio/Dados Trade Turístico/tecnologia e educação ambiental. pdf $>$. Acesso em: 20 out. 2016.

RUCHKYS, Úrsula Azevedo. Geoparques e a Musealização do Território: um Estudo estudo sobre o Quadrilátero Ferrífero. Revista do Instituto de Geociências -USP. São Paulo, v. 5, p.35-46, out. 2009.

RUSCHMANN, Doris. Turismo e Planejamento Sustentável: A proteção do Meio Ambiente. 16. ed. Campinas: Papirus, 2012. 192 p.

SANTOS, Silvio Coelho dos. Encontro de estranhos além do "mar oceano". Etnográfica, Lisboa, v. 2, n. 7, p.432448, nov. 2003. Semestral. Disponível em: <http://ceas.iscte.pt/etnografica/docs/vol_07/N2/Vol_vii_N2_431-448. pdf>. Acesso em: 09 out. 2016.

SCHMIGUEL, Karla; VARGAS, Karine Bueno; TRATZ, Eliza de Belém. Configuração geológico-geomorfológica e evolução da paisagem dos canyons da região de Campos de Cima da Serra -Sul do Brasil. Observatório Geográfico da América Latina. México, 2009. Disponível em: www.observatoriogeograficoamericalatina.org.mx/ egal12/Procesosambientales/.../21.pdf

SCOTESE, Christopher R. Paleomap Project. Disponível em: www.scotese.com. Acesso em: 15 out. 2016.

PÚBLICA, Sociedade. Parque Nacional Serra Geral. 2016. Disponível em: <http://sociedadepublica.com.br/ parque-nacional-da-serra-geral/> . Acesso em: 14 out. 2016. 
ROSA, Tarcísio Roldão da; ROCHA, Isa de Oliveira. Proposta de planejamento regional no extremo sul de Santa Catarina: projeto geoparque Caminhos dos Cânions do Sul. In: Seminário Nacional de Planejamento e Desenvolvimento, 2, 2014, Florianópolis. XIV Simpósio de Geografia da UDESC. Florianópolis: Universidade do Estado de Santa Catarina (UDESC), 2014. v. 1, p. 1 - 17.

WILDNER, Wilson; ORLANDI FILHO, Vitório; GIFFONI, Luís Edmundo. Itaimbezinho e Fortaleza: RS e SC. In: WINGE, Manfredo et al (Eded.). Sítios Geológicos e Paleontológicos do Brasil. 2. ed. Brasília: CprmCPRM, 2009. Cap. 4. p. 99-110. (Volume 2). Disponível em: <http://sigep.cprm.gov.br/>. Acesso em: 26 set. 2016.

WILDNER, Wilson; ORLANDI FILHO, Vitório; GIFFONI, Luís Edmundo. Itaimbezinho e Fortaleza, RS e SC: Magníficos canyons esculpidos nas escarpas Aparados da Serra do planalto vulcânico da Bacia do Paraná. s.d. Disponível em: <http://sigep.cprm.gov.br/sitio050/sitio050_impresso.pdf>. Acesso em: 16 nov. 2016. 